\title{
Community Intervention Strategies to Youth Alcoholism: A Case of Kinyago Village, Gatundu District, Kenya.
}

\author{
Alice Gikandi \\ Wanguigikandi06@yahoo.com \\ PhD Candidate, The Catholic University of Eastern Africa
}

\begin{abstract}
The intensity of alcohol abuse in Kenya has been a major concern in recent years, more so affecting the youth. Alcoholism continues to affect many families in Kenya usually leaving entire families deeply divided. In many parts of central Kenya, alcoholism has been blamed on the decreasing birth rates. It is therefore evident that if this problem is not checked, the entire society will crumble. This study focused on the youth aged between ages 15-25 years and was carried out in Kinyago Village, Gatundu District, where the problem of youth alcoholism was noted as highly prevalent. The study set out to find out the extent to which alcoholism affects the productivity of the youth, and to understand how the youth cope with the challenges of alcoholism in Kinyago village, Gatundu District. Survey research design was used in this study. Simple random sampling was used to gather a total of 140 respondents. Structured questionnaires were used to collect data from the youth and unstructured interviews collected data from the key informants. The raw data collected were processed using the SPSS statistical package; both descriptive and inferential statistics were used to analyze the data. Results indicated that the community and government were making attempts in mitigating the effects of alcoholism among the youth. Some of the methods used to curb youth alcoholism include police raids (21\%), parents' talks (16\%), Youth fund (14\%), chiefs' barazas 13\%, and games tournaments (5\%) among others.
\end{abstract}

Key Words: Alcoholism, Youth, Intervention.

\section{BACKGROUND}

Majority of people believe that alcoholism affects people of certain ages, races, sex, religion, or social class (Clausen, 2012). Some others believe that alcoholism is a 'men only' phenomenon. But this is not the case and the truth is that these categories have little to do with alcohol consumption and addiction. Anyone can be involved in alcoholism. The youth are also not left behind and are involved in alcoholism both in the urban and the rural areas. Thus, consumption of alcohol is no longer restricted to the adults or special social-cultural occasions. The youth say that they too drink to reduce tension and frustration, relieve boredom and fatigue but the use of alcohol for personal gratification and temporary adaptation carries a very high price tag (Parry,2013).Thus, what is intended as adaptive behavior is maladaptive in the long run. The productivity of the youth is adversely affected, considering the kind of alcohol available to them which is not only harmful but is definitely unfit for human consumption (NACADA, 2014).

According to Zuskin, (2014), many people drink alcohol occasionally like during a night out with colleagues or a company party. Others drink moderately only after experiencing or encountering various issues in life such as divorce, or death of a close family member. Others may drink moderate amounts of alcohol on a more regular basis as they socialize with friends usually referred to as social drinking. For women and those over the age of 65, a moderate amount means no more than two drinks per day (pregnant women are advised not to drink alcohol). Men should not drink more than four units a day. Drinking at these levels according to the World Health Organization (WHO, 2014), "usually is not associated with health risks and can help prevent certain forms of heart diseases". Under certain circumstances, however, even moderate drinking is not risk free. It can impair coordination and thinking, affect driving or operation of machinery (Rehm, 2013).

At more than moderate levels, alcohol drinkers are at risk of serious problems with health, family, friends, and co- workers. Drinking above the recommended safe limits is hazardous and increases the risk of developing diseases such as cirrhosis (liver damage), damage to the pancreas, cancers, heart problems, sexual problems and many other conditions (WHO, 2012). Problem drinking is where you continue to drink heavily even though you have caused harm or are causing harm or problems to yourself, family, work-place or society (ILO, 2014). The next level is the alcohol dependence (addiction) which is a serious situation whereby drinking alcohol takes high priority in your life and involves drinking every day to prevent unpleasant withdrawal symptoms.

The Kenyan youth have unfortunately drunk alcohol to this dangerous level and hence is a serious problem that needs to be addressed (NACADA, 2014). The intensity of alcohol and drug abuse has been a major 
concern all along, but more so recently. According to Mokdad, (2015) "seldom does a day go by when a person is not confronted with some aspects of that enormous and burgeoning public health problem". Alcohol is undoubtedly the most popular drug of abuse in Kenya more so affecting the youth who have the curiosity to find out what it is like (UNODC, 2012), thus the purpose of this study.

\section{Youth alcoholism as a social problem}

Alcohol is one of the few mood altering substances that is socially and legally used by individuals and not everyone who uses alcohol has problems or ends up getting problems (WHO, 2012). It is important to note that there are categories of people and individuals who drink alcohol but are able to control themselves and the alcohol usage in a manner that it ends up not causing them or their families any harm (Zawaira,2009). However, majority are unable to control alcohol usage resulting to grief problems and pain to those around them. The youth who use alcohol constantly end up performing poorly in school, eventually dropping out of the school system and if working, performs poorly in their place of work ending up abandoning employment or being sacked (NACADA, 2014).

Alcoholism causes social conflicts between alcohol abusing individuals and the majority in the social group (Klingemann, 2015). Alcoholism refers to those situations whereby persons or groups abuse alcohol in such a way that they attract the disapproval of the rest of the society usually referred to as excessive or deviant use of alcohol (WHO, 2014).). The Kenyan youth are abusing alcohol to the extent that everybody is up in arms complaining and condemning the bad behavior adopted by the youth. In Kenya today, very many schools are going on strike destroying and burning school property and alcoholism has been alleged to be the problem behind it all (Chesang, 2013).

The social problems arising from alcoholism can be significant. Being drunk or having a hung over during office hours can result to loss of employment, leading to financial problems including living quarters (ILO, 2014). Many working youth have lost their jobs this way leaving them with no source of income hence unable to finance their day to day operations. An alcoholic's behavior and the mental impairment while drunk do profoundly impact surrounding family and friends, leading to marital conflict and divorce, or contribute to domestic violence (Gayford, 2013). This can contribute to lasting damage to the emotional development of the young alcoholics' children even after they get to adulthood. The alcoholic himself could suffer from loss of respect from others who may see the problem as self-inflicted (WHO, 2014). It is therefore no wonder that the youth in alcoholism develop and suffer negative self-image and poor self-esteem.

\section{METHODS}

\section{Research Design}

The chapter focuses on the research design used in this study. Creswell, (2015) defines a research design as a plan, structure and strategy of investigation conceived so as to obtain answers to research questions and to control variance. According to Glesen, (2014)) "research design is the arrangement of conditions for collection and analysis of data in a manner that aims to combine relevance to research purpose with economy in procedure" It is the research design that guides the research in collecting or gathering, analyzing and interpreting observed facts. This study adopted the case study research design to uncover what goes on as villagers are consumed by alcoholism. A case study is an in-depth comprehensive study of a person, a social group, an episode, a process, a situation, a programme, a community, an institution or any other social unit (Teddie et al, 2011). A sample size of 140 participants was selected using simple random sampling.

\section{Site selection}

The study aimed to understand the effects of alcoholism on the productivity of the youth in Kinyago village, Ng'enda location, Gatundu District. It is about $40 \mathrm{~km}$ from Nairobi. This is a village whereby the brewing and selling of alcohol has been passed on from generation to generation. This particular village was selected for its uniqueness as a drugs den and has actually adversely affected the environs namely Wamuguthuko, Kahuguini, Kimunyu, Gachoka, and Ng'enda. These areas have a high population density and hence many people, young, old and even women drink in this village. It is very widely known for chang'aa brewing, drinking and selling. It is an area that has survived the test of times. The police also know it all because they have made futile efforts to curb the menace over time. The area has severally been covered by the media and television stations highlighting battles with the police as they try to curb the menace (Daily nation, 18 September 2006).

The selection of this village was done purposively. It is an area not far from the capital city of Nairobi where the slum areas are well known for the illicit brews. Much of the alcoholic drinks sold here previously used to come from the slums in Nairobi, transported over-night to maintain supplies for the following day in the village. This is how the alcoholic culture has spread rapidly into the rural areas. But for the last 15 years the 
locals have learned how to brew the chang'aa locally and have perfected the act such that all the chang'aa consumed here and in the surrounding villages is brewed within the village.

The research site was appropriate in that it is accessible and the site is full of various drinking activities. People keep flowing in to drink and the supplies are properly maintained. Each of these people visit a particular household where they drink and every alcohol seller has herlhis own clients. The human relations here are so strong that none would dare jeopardize them. The research site is an area that the researcher had heard so much about and hence was a good opportunity to verify what has always been said about the village about alcoholism. The researcher was familiar with the environment though not with this particular village and could actually speak the language of the locals. This went a long way in enabling penetration into the networks to be able to carry out the research.

\section{RESULTS}

Interventions to contain the problem of youth alcoholism

There has been several measures put in place to stop youth from drinking at the community as well as at the national level. The youth were asked to identify these measures. This shows that the community and the government are aware that drinking can have devastating effects on the populace and have been trying to stop the escalation of the same.

Figure 1 represents the findings on measures put in place to stop youth from drinking.

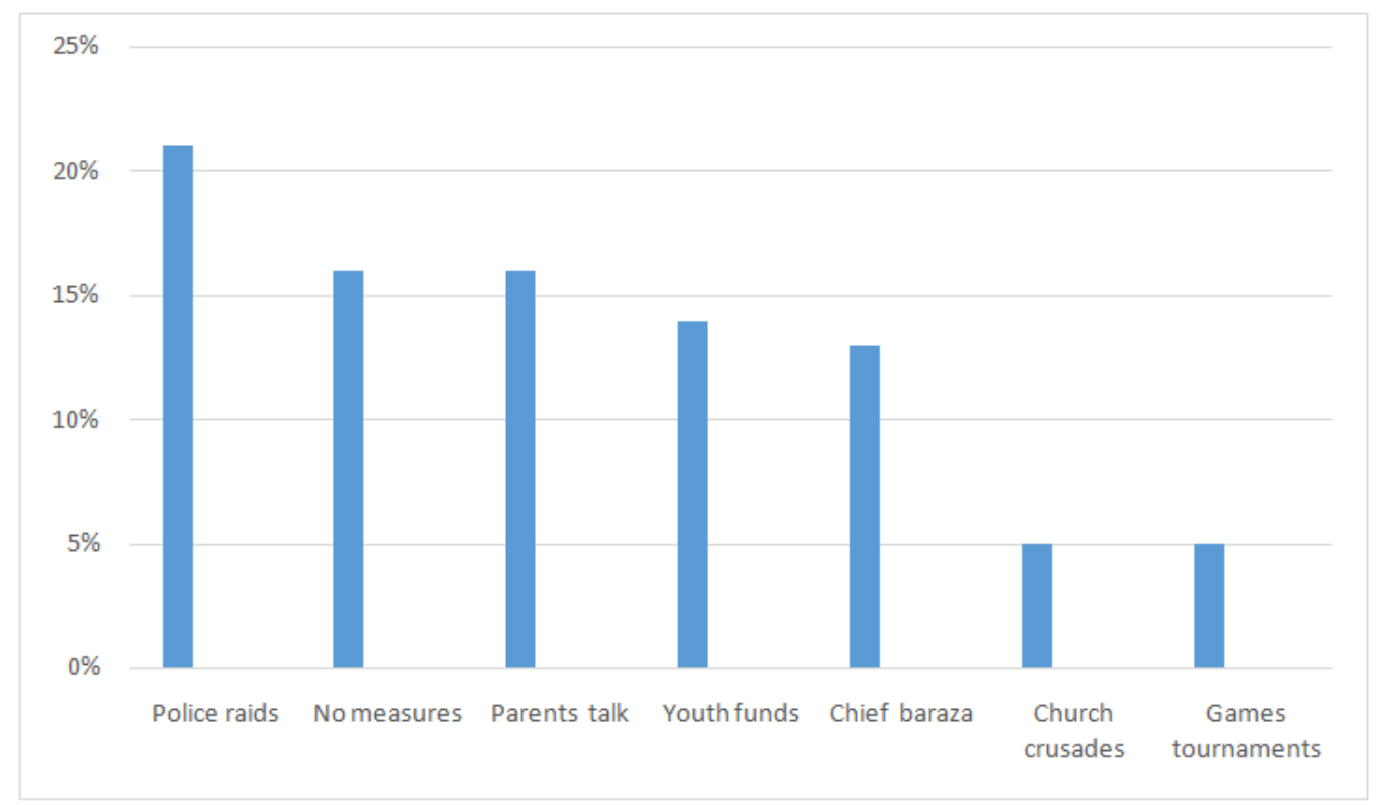

Fig. 1: Measures put in place to stop youth from drinking.

Figure 1 shows the various measures put in place by the various stakeholders to stop youth from drinking. The measures are quite diverse and varied. The respondents were asked to identify the measures put in place and $21 \%$ said that the police raid the area in a bid to stop youth from drinking, $16 \%$ said that no measures have been put in place, and another $16 \%$ said that parents talk to their children. Another 14\% said that the youth funds is a measure to engage the youth to stop them from drinking and $13 \%$ said that the chief organizes public barazas, 5\% reported that churches hold crusades and seminars and another 5\% reported that games are organized to keep the youth busy. The youth felt that there are these efforts put up by the various stakeholders but they have not been concretized and hence remain at a theoretical level.

This shows that various stakeholders have tried to address the problem of youth alcoholism but the youth felt that measures have not yielded fruit in stopping them from drinking. There has been various measures taken by stakeholders to stop youth from drinking. This is in recognition of the fact that alcoholism is a serious problem that needs to be addressed. The stakeholders here are the youth themselves, parents, schools/teachers, Government of Kenya and others. These are the ones who are close to the youth in terms of being the care takers.

\section{DISCUSSION}

From the research findings, there has been some mitigation measures put in place to deal with the problem of alcoholism among the Kenyan youth at the community and national levels. The respondents (21\%) 
said that police conduct raids so as to be able to scare and stop those making, selling and drinking chang'aa. Some are even detained in police stations and others taken to court where some are fined and even jailed. The handling of alcoholism as a moral issue has been challenged across the world. Several studies conceptualize alcoholism as a disease which can be treated (Yatan, Rajeev, Anju \& Deepak, 2014). Other studies also associate alcoholism with other social and psychological underlying issues such as stress (Kathleen \& Susan, 1999). This implies that police raids may only confine the alcoholics but not necessarily end their craving for alcohol. This study agrees with police raids only if it is directed at suppressing alcohol supply and not as a means of reforming the young people.

The respondents (13\%) said that chiefs and the local administration organize regular public barazas as a forum to reach out on the youth, talk to them about positive attributes in life. The respondents reported that parents $(16 \%)$ have tried hard to talk to the youth to get out of alcoholism and tried to show them the evils of alcoholism. The youth themselves are expected to put in some efforts to stop drinking but the youth according to the study rated their efforts as very little and ineffective. The attempt to hold seminars, and talk to the youth is a positive strategy that if well utilized could help deal with psychological and social issues that pressure the young people into addiction. These strategies are in agreement with the findings of Wills and Filer (1996) who propose stress coping mechanism as a means of addressing youth alcoholism.

The respondents $(5 \%)$ reported that churches have also participated in the elimination of alcoholism in the youth by organizing crusades and seminars targeting the youth. In these crusades and seminars, a lot of prayers are offered for the youth and some were touched and changed. The use of spirituality in elimination of alcoholism is congruent with empirical study findings (Warfield and Goldstein, 1996). However spirituality should not be imposed on the youth but should seek to address their issues with respect to their individual values. If well applied this could complement in alleviation of alcoholism. In schools, the teachers have also had some input by talking to the youth trying to instill some morals in their lives. The government has been in the forefront and has come up with various policies for alcohol eradication. A ministry in government has been set up to address youth issues and also the youth fund meant to provide financial assistance to the youth to set up businesses that would occupy them.

The mitigation measures have been put in place at the community and at the national levels. However the research findings indicate that the measures have not been effective and appropriate in solving the problem of youth alcoholism. The respondents (90\%) agreed with a statement that no appropriate efforts have been put in place to solve the problem of drinking among the youth, and $96 \%$ agreed with the statement that the authorities are not doing enough to help youth stop drinking. The authorities are said not to be doing enough to address the problem. The key informants and the respondents reported that the government officers charged with the responsibility of implementing policies are said to be corrupt. Instead of going to raid the alcohol dens, they get there, are bribed and therefore do nothing about the problem. The youth funds have not trickled down to the villages and hence the benefit has not reached the youth. Many of the efforts are said to be at a theoretical level and not practical.

\section{REFERENCES}

[1]. Clausen T, (2012).Diverse alcohol drinking patterns in 20 African countries. University of Hull, England.

[2]. Creswell, J. (2015). Research design: Qualitative and quantitative approaches. Thousand Oaks: Sage publications

[3]. Gayford, J. J. (2013). Battered wives. In J. P. Martin (Ed.), Violence and the family. Woking, UK: Wiley

[4]. Glesen C. (2014). Becoming a Qualitative Researchers: An introduction (4 $4^{\text {th }}$ Edition). Boston: Pearson.

[5]. Kathleen, T.B., \& Susan, C.S. (1999). The role of stress in alcohol use, alcoholism treatment and relapse. Alcohol Research and Health. Greenhaven Press, Inc.

[6]. Klingemann, H. (2015). Mapping the social consequences of alcohol consumption. Dordrecht, Kluwer Academic Publishers.

[7]. International Labour Organization (ILO) 2014. Alcoholism and labour output, Geneva, ILO.

[8]. Mokdad, A. (2015). Binge drinking, a problem that cannot be ignored. Preventive Medicine. Greenhaven Press, Inc.

[9]. NACADA, 2014. National Survey on Drug Abuse in Kenya http://www.nacada.go.ke/component/content/article/19highlights/71-drug-highlights.

[10]. The National Agency for the Campaign Against Drug Abuse (NACADA) 2014.General information on drug and substance abuse, preventive education. Government Press, Nairobi, Kenya.

[11]. Parry, C.(2013). Alcohol problem in developing counties: challenges for the new millennium. Alcohol in developing countries. Sage publications

[12]. Rehm, J. (2013). The relationship of average volume of alcohol consumption and patterns of drinking to burden of disease: An overview. Greenhaven Press, Inc.

[13]. Teddie, C. (2011). Foundations of research methods designs. Thousand Oaks: Sage

[14]. United Nations Office on Drugs and Crime. (2012). The contemporary drug problem: Characteristics, pattern and driving factors. World drug report 2012. Retrieved from United Nations Office on Drugs and Crime Website.

[15]. Warfield, R.D. \& Golden, M.B (1996). Spirituality: The key to recovery from alcoholism. Counseling Values. Rutledge Publishers. 
[16]. Willis, T.A, \& Filer, M. (1996). Stress- coping model of adolescent substance use. Child Psychol. Longman, New York

[17]. World Health Organization (WHO), (2012). Alcoholism, a health risk. WHO, Geneva

[18]. World Health Organization (WHO) 2014. Alcoholism as a social problem. WHO, Geneva.

[19]. Yatan, P.S., Rajeev, R., Anju, D., \& Deepak, Y. (2014).Experiences from a community based substance use treatment centre in an urban resettlement colony in India. Journal of Addiction, Vol. 2014

[20]. Zawaira, F. (2009). The burden of alcohol consumption in the African Region. WHO, Geneva.

[21]. Zuskin E, (2014). Alcoholism and how it affects health and working capacity. Greenhaven Press, Inc. 